\title{
Blended versus face-to-face: comparing student performance in a therapeutics class
}

\author{
Ângelo Jesus ${ }^{1}$, Maria João Gomes², Agostinho Cruz ${ }^{1}$ \\ ${ }^{1}$ Instituto Politécnico do Porto, Escola Superior de Saúde, Porto, Portugal \\ ${ }^{2}$ Research Centre on Education, Instituto de Educação, Universidade do Minho, Braga, Portugal
}

\begin{abstract}
Therapeutics is a very complex subject for every pharmacy student, since it requires the application of knowledge from several other disciplines. The study of therapeutics is often done in case-based learning in order to promote reflective thinking and give a scenario as real as possible. The objective of this study was to compare student performance between faceto-face $(n=54)$ and blended learning $(n=56)$ approaches to the teaching of therapeutics. They can confirm that there are statistically significant differences $(p<0.05)$ between the final exam scores from both groups, being that the b-learning group achieved higher scores. Blended learning seems to be an effective way to teach therapeutics, following pre-established teaching methods, and above all, does not negatively affect student performance. It also provides new learning environments and strategies, and promotes the development of new skills such as learning and collaborating online, which may be relevant in a networked knowledge society.
\end{abstract}

\section{Introduction}

As a future health professional, the student is required to develop a vast and intricate variety of skills, to take into account large amounts of factual information, and to practice technical and technological procedures [1]. In an effort to prepare future health professionals to meet the challenging demands of the profession, teachers are encouraged to promote student's higher-order thinking and collaborative learning and to increase students' motivation [2]. One way of achieving these objectives is to complement traditional learning methods with real-life situations using, e.g. case-based learning $(\mathrm{CBL})$ or problem-based learning (PBL). Dewey [3] suggests that students should be presented with real-life problems and then helped to discover the information required to solve them. The author advocated reflection as a process for problem solving. Dewey saw reflection as a specialised form of thinking. He described it as: 'a kind of thinking that consists in turning a subject over in the mind and giving it serious thought'. Some higher education institutions (HEIs), like McMaster University, Canada, recognised the importance of Dewey's ideas, and designed a PBL curriculum for medical students [4]. The objective was to promote learner-centred, small group, interactive learning experiences. Professors ought to facilitate or tutor, rather than just lecture. A curriculum that presents problem solving activities tends to trigger interdisciplinary learning opportunities as opposed to curriculum contained in discipline-based texts and presentations [5]. Therefore, students are able to pursue the learning issues by their own, in contrast to students in a more traditional curriculum, who might focus on identifying what material the professor will include on the exam [5]. After McMaster University's experience was massively divulged, several medical and allied health science programs also made changes to their curriculum in order to incorporate one of more aspects of PBL, CBL or similar approaches.

We have debated, in a previous work [6], the different contexts in which PBL and CBL are implemented, and on this paper, we will focus our attention to CBL, more specifically a case-based approach to therapeutics.

\subsection{Case-based learning}

CBL aims to promote authentic learning because the cases place events in a real-life context [7]. The major difference between CBL and PBL is that the latter requires no prior experience or understanding of the subject matter, whereas CBL requires the students to have some prior knowledge. The cases per se are generally written as problems with a background of a patient/ clinical situation as well as support information, such as vital signs, symptoms and laboratory results.

CBL promotes the consolidation and integration of learning activities [7,8] and allows students to develop a collaborative approach to their education [9]. CBL is also known for encouraging self-assessment and critical thinking, development of intrinsic and extrinsic motivation, promote the integration of knowledge and practice, allowing scientific inquiry and the development of support provision for their conclusions [7, 10]. $\mathrm{CBL}$ requires students to recall previously covered material to solve clinical cases [11]. As such, CBL is more supportive of the learner than PBL, since students in PBL are expected to locate their own resources.

CBL and scientific reasoning are closely related to critical thinking; they all use reasoning to solve a problem valuing the clarity, relevance and accuracy, while testing theories and searching for solutions [12]. CBL aims to develop critical appraisal skills under the concept of 'learning by doing' and serves as a primer, for professional clinical skills [13].

The use of CBL approach is, however; time consuming. Another drawback of its use may be the size of the class: CBL usually demands small groups from 10 to 14 students allowing the teacher to monitor the activity and the quality of the students' work, perform a closer assessment of the process, give feedback and ask the necessary questions [14]. Adaptation from teachers and institutions is required, to successfully integrate $\mathrm{CBL}$ in the curriculum.

\subsection{Case studies in therapeutics}

Therapeutics can be one of the most defiant disciplines for the pharmacy students. A typical example can be set with antitussive drugs. While in pharmacology the student must study, and understand, absorption, metabolism and excretion of drugs, mechanism of action, side effects and interactions; in therapeutics, the student is confronted with a patient with diabetes, who's taking antidepressants and has a dry cough. In addition to the description of a specific problem, a case study should include additional information necessary to place the scenario in context and should 
foster an analysis of possible solutions or actions arising from the situation. The purpose of using a case study is to present the student with a real-life scenario, so that he may be able to devise reasonable and workable solutions. A good case study must not provide answers. Rather, it should raise questions and allow the students to work through the decision-making process. As such, a teaching environment generated in $\mathrm{CBL}$ is one where the student must actively participate to meet the learning objectives.

\subsection{Assessment}

Traditional ways of assessment are not entirely compatible with the nature of CBL. This approach assumes that the student has a leading role in the classroom, and the teacher should focus not only on the final product but also the process. In this type of learning approach we should value the work of the group, communication skills/reasoning course and the ability to solve the case itself. Nevertheless, it is also a valid concern of instructors to ensure the commitment of the student to follow the theoretical background. As such, individual and group assessments should be performed. Assessment in CBL can seem challenging. It is probably more subjective than some other methods and some teachers may be uncomfortable with that. However, with careful lesson planning and preparation, assessment in CBL can be done with efficiency and fairly. Students, also can be uncomfortable with assessment, especially those who are accustomed to multiple choice or other kind of assessment that always have clear right and wrong answers. Wassermann [15] asserts that the learning goals and objectives established at the beginning are key. Once those are clear, the next step is to establish standards and let students know exactly what is expected of them. When this approach is face-to-face, we use a variety of assessment techniques, both summative and formative, the latter for providing corrective feedback [16]. For individual assessment, small tests are given at the beginning of the class, relating the contents, the student should explore before coming to the class. For group assessment, a benchmark was developed, contemplating the following items:

(a) ability to work in groups;

(b) objectivity and consistency;

(c) using correct scientific language;

(d) reference to 'mandatory' topics, depending on the case;

(e) communicating ideas and opinions;

(f) making and defending ideas.

In the face-to-face classes, the group assessment consisted in direct observation and a debate between all groups and the teacher.

The transition from classroom learning to virtual learning, brings with it new challenges for the assessment process. First, develop and implement assessment strategies that are able to measure product and process, but also lessen or otherwise prevent copying or plagiarism situations while still ensuring the student's identity [17]. Distance education has always been faced with student assessment issues, particularly with regard to summative assessment with classification function [17]. In this specific project (b-learning), we defined the need to assess students for their individual skills and for their contributions to the group [18]. For individual assessment, quizzes, glossary and participation in online discussion forums were implemented. For group assessment, we favoured the construction of group e-portfolios. In order to increase the effectiveness of student's performance, we considered the following points [19]:

(a) select clearly aligned assessment tasks with defined learning objectives;

(b) provide students, in advance or at the time of evaluation, the scores assigned to each item;

(c) communicate to students prior to assessment, standards and rules associated with the implementation thereof;

(d) encourage students to complete formative assessments; (e) Interpret the performances of students, comparing them with those previously developed, which are provided to students upon completion of the evaluation activity.

\subsection{Blended learning}

A unified concept of blended learning is not always easy, not only because there are multiple perspectives among authors, but also because the linguistic idiosyncrasies of each language. The first references to the term came from the industry (with an emphasis on lifelong learning), but recently, the focus of blended learning has been accentuated at higher education level [20]. In a time where the existing literature on blended learning rested mainly on issues of 'how to', oriented to industry and services, several authors [21, 22] presented us definitions of blended learning settings, as classic training programs (instructor-led) supplemented with electronic components (CD-ROM, multimedia technologies, voicemail, email, animations and streaming). At this time, the main audience consisted of managers and entrepreneurs in the industrial and commercial sector, whose objective would be to create more effective, fast and cheaper training programs, for lifelong training of employees. Therefore, more emphasis was given to practical questions of 'How can this help your business? How to organise, implement and evaluate a training program of this kind?'. The blended learning was praised as an effective and less expensive response to the problems of continuing education in the private sector.

In a more academic perspective, Whitelock and Jelfs [23] suggest three different types of b-learning:

(a) 'the combination of traditional learning with web-based online approaches;

(b) the combination of media and tools employed in an e-learning environment;

(c) the combination of a number of pedagogic approaches, irrespective of learning technology use.'

In this sequence, Driscoll [24] makes a proposal, with the identification of four concepts:

(a) 'combining or mixing web-based technology to accomplish an educational goal;

(b) combining pedagogical approaches to produce an optimal learning outcome with or without instructional technology;

(c) combining any form of instructional technology with face-toface instructor led training;

(d) combining instructional technology with actual educational tasks.'

In a different perspective, Lencastre [25] deals with b-learning, focusing on the concepts of synchronous and asynchronous. According to the author, synchronous moments occur simultaneously for all stakeholders, i.e. all students have virtual access to the same information (whether textual, visual or auditory) at the same time interval, as if they were in a classroom. By contrast, in asynchronous moments (forum, email etc.), learning happens at different times for each participant, according to the time and availability of each student. Blended learning will therefore consist in a mixed use of both approaches (synchronous and asynchronous) [25]. Nevertheless, the author safeguards, that synchronous and asynchronous communication should not be distinguished by embedded technologies, but by the goals.

Despite the numerous definitions, usually blended learning is associated with the integrated, effective and systematic combination of virtual activities (usually supported by a learning management system - LMS), combined with face-to-face interaction, in order to take advantage of the benefits provided by synchronous and asynchronous learning situations and contexts [26-32]. In this definition, we do not report the 'actual time' of virtual activities, but the effective use of pedagogical potential inherent in each of them, emphasising the need for correct instructional design $[20,31,33]$ and safeguarding the potential to support a collaborative learning [34-36]. 


\section{Chronic venous insufficiency.}

Based on professional experience of the instructor and supported by: Pharmacological treatment of primary chronic venous disease: rationale, results and unanswered questions.(2011) European journal of vascular and endovascular surgery: the official journal of the European Society for Vascular Surgery, $41(1)$

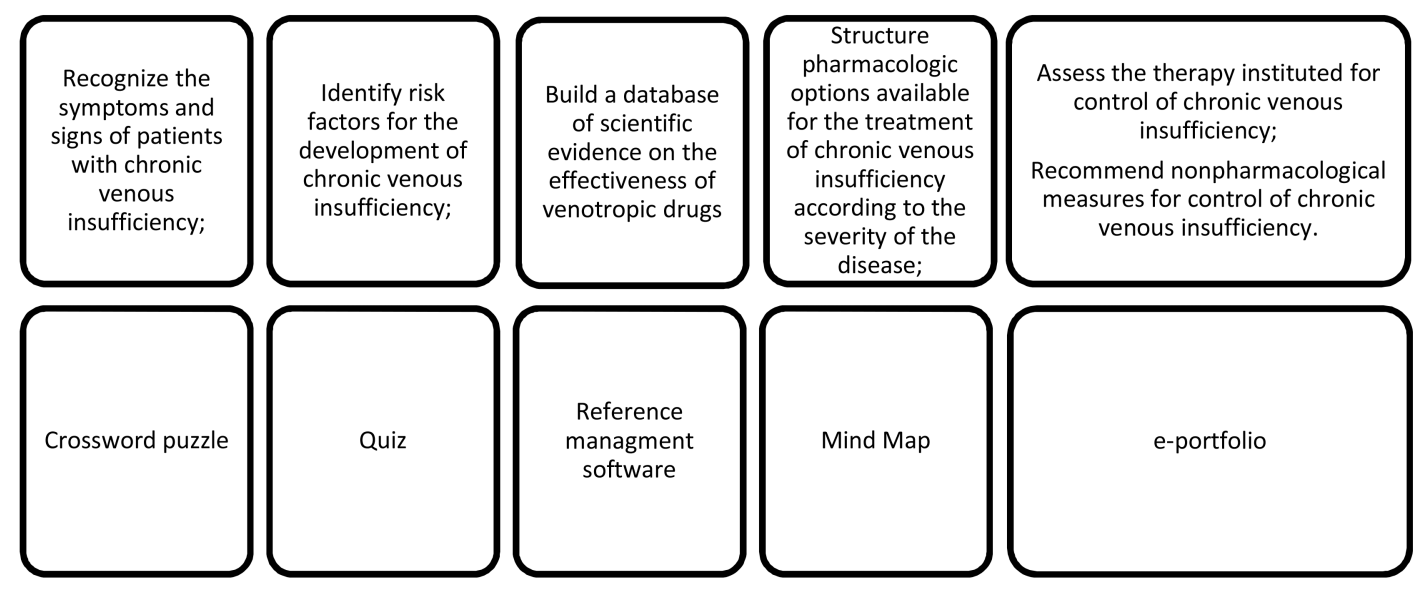

Fig. 1 Example of topics, learning objectives and assessments strategies for the blended learning approach

\section{Methods}

To design the therapeutics training program, we considered educational goals, pedagogical models, student's characteristics, strategies and instructional technologies that best fit the expectations of the teacher, the student and the educational context, enabling greater efficiency of the process as a whole. As for instructional model, we used the MIPO model - integration model by objectives [37]. The term 'integration by objectives' reinforces the importance of the integration of web technologies in the educational context, supported by the objectives of learning set for the unit and for the course. This approach has the intention to reinforce the importance of learning objectives in the design and implementation of online activities. Blended learning contents were made exclusively with free access authoring tools like Xerte ${ }^{\odot}$ (The Xerte Project-Nottingham University), TimeGlider ${ }^{\odot}$ (Mnemograph LLC), VUVOX ${ }^{\odot}$ (VUVOX Network, inc.),

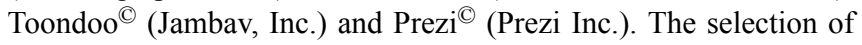
these tools was based on their usability, the diversity of media and activities allowed to incorporate and the aesthetic aspect of the final result. The articulation of digital content with the learning objectives, teaching strategies and subsequent assessment techniques, deserved a profound attention, so that as a whole it could provide relevant and meaningful learning experience (Fig. 1).

\subsection{Case studies}

The cases were based, or adapted from real situations. They were normally ill-defined so that the students could discover what course of action to pursue [6]. Sometimes the cases needed to be simplified to allow students to focus on one main therapeutic area. However, as we grew in complexity (settings in which patients often are receiving multiple medications - especially elderly patients) it is important to gradually expose students to cases with multiple issues and drug-related problems. This helps to set priorities while settling multiple drug-related problems [38]. By assuring the opportunity to gradually work through more difficult topics, students were also able to gain the required knowledge and develop their skills in assessment and management of drug therapy [38].

\subsection{Class dynamics}

Journal articles or reports, as well as a class guide, were presented to the students through the LMS, a week before the class. By doing this we were trying to ensure that the students focused on specific issues, in order to better understand the clinical case that will only be presented in class. The students were divided into case-study groups of about four students. Development of group dynamics was an important element of the course, and best achieved if students had to work with colleagues who they did not necessarily know well. The case study per se has the description of the situation and a set of questions/guidelines that the students had to address during the class. Students should then collaborate with their group members, in order to present solutions to the problem.

It is their responsibility to:

(a) recognise symptoms and correlate them with the illness;

(b) locate critical information to clarify and solve the problem;

(c) explain pharmaceutical care problems in the case;

(d) identify drug-interactions;

(e) identify and select reasonable therapeutic alternatives and goals;

(f) educating the patient.

In face-to-face classes, a debate was promoted at the end of the session, and the students were assessed accordingly.

In the blended learning sessions, the contributions of each group should be made on an e-portfolio, where the students could collaborate and also enrich their contributions with links, videos, text, images or sounds.

\subsection{Assessment strategies for digital CBL}

To ensure or encourage student commitment, we settled a number of individual assessment situations, based on quizzes, multiple choice, blank spaces and/or true and false questions. The development of these activities was relatively easy, since the majority of learning management systems have specific features for assessment, just like Moodle (Moodle Pty Ltd), which we adopted as support to the activities of this course. Moreover, there are applications that could provide interesting assessment scenarios (like HotPotatoes from Half Baked Software Inc) that have compatibility with most LMSs. However, depend solely on this type of assessment is inconsistent with the principles of CBL, because it does not provide guarantees for learning complex cognitive goals, as demanded in HEI [39-41]. Nevertheless, this assessment option, simple and quick, can be an ideal support for the training and self-assessments ratings, contributing to the selfregulation of the students, without representing a big increase of time and effort from the teacher. 
Learning therapeutics involves the mastery of several specific terms and concepts of the medical and pharmaceutical field. To foster understanding of these terms, we proposed a collective glossary. All students had to participate, at least once, with the introduction of a term relating to the cases. The term in the glossary was available for classification and review by the teacher, should be accompanied by the original source/reference and could be re-edited by the author. By the end of the online module, 49 entries were introduced in the glossary, and $80 \%$ of students participated actively.

We also devised a forum. Forums are asynchronous collaborative tools, with moderated or non-moderated discussions, used in e-learning platforms that aim to promote sharing of knowledge. The idea is that what a student may need to know is probably also valuable knowledge for other students. By sharing ideas and impressions, the knowledge is spread inside the learning community in a collaborative way which can contribute to the learning outcome of every participant [42]. However, participation in forums is not always seen by students as a beneficial mechanism. In our project, the implementation of the forum was the most challenging one. Quantitative assessment of forum contributions was easily obtained from the LMS records. As for the qualitative assessment, several models are available, and we used like the one proposed Yang et al. [43].

Finally, we also used e-portfolios. The construction of the eportfolio was the sole responsibility of the students. Their work was progressively constructed, by all the members of the group, using Wikispaces ${ }^{\odot}$ (Tangient LLC). The choice of the e-portfolio platform was based on its features regarding the integration of text, images, links, videos, audio, documents, presentations and other features, it's privacy editing, access and registration options, that could provide in detail, the contributions of each member of the group. Students created a new page for each case (one a week), where they could explore the different topics regarding the disease and therapy for that patient or group of patients. A total of 20, very different portfolios, were developed. Their systematic analysis allowed the observation of commitment and motivation of the students, and formed the basis of a qualitative assessment.

\subsection{Written test and performance}

Though one of the initial objectives was to move away from reliance on multiple choice and short answer testing, this objective has not been fully accomplished. At the end of the semester, a final exam is still performed. The questions relate to the clinical cases explored in the classes, and the questions are written in order to promote reflection on the topic at hand. To determine the project's impact on student's performance, we developed a quasiexperimental study [44-46], during two academic years. Two different groups of students were part of the experiment. The first group $(n=54)$ was taught face-to-face. The second group $(n=56)$ was taught in blended learning. Topics, learning objectives and teachers were the same. The blended learning group had two faceto-face sessions. Final exam scores were used in order to make more objective comparisons.

Table 1 Results relating to normal distribution and homogeneity of variance

\begin{tabular}{lccc}
\hline $\begin{array}{l}\text { Final assessment (exam } \\
\text { scores) }\end{array}$ & Sum of squares $d f$ & $F$ & Sig. \\
\hline between groups & 19,211 & 1 & $24,039 \mathbf{0 . 0 0 0}$ \\
within groups & 86,308 & 108 & \\
total & 105,519 & 109 & \\
\hline
\end{tabular}

Bold values represent the values of $p$.

Table 2 Results $t$-test for independent samples

\begin{tabular}{lcccc}
\hline \multicolumn{2}{l}{ Levene's test } & \multicolumn{3}{c}{ t-Test for equality of means } \\
$\mathrm{F}$ & Sig. & $\mathrm{t}$ & $\mathrm{df}$ & Sig. (2-tailed) \\
\hline 0.045 & 0.832 & -4.903 & 108 & $\mathbf{0 . 0 0 0}$ \\
\hline
\end{tabular}

Bold values represent the values of $p$

\section{Results}

Student's characteristics were assessed prior to the implementation of the courses. Both groups have a median age of 19 years old, they had never taken an online course before and none of them had prior experience with the topics being covered. Students were allocated in a face-to-face group $(n=54)$ and a blended learning group $(n=$ 56). To verify that the quantitative variables have a normal distribution, we applied the Kolmogorov-Smirnov test $(p=0.578)$. We continued statistical analysis using a Levene's test for homogeneity of variance analysis $(p=0.832)$. Comparing the values of the Levene test with one-way ANOVA (Table 1), it appears that with $p<0.05(p=0.000)$, there is at least one difference between the groups. We proceed with the application of the t-student test for independent samples.

Since $p=0.000$ (Table 2), we can confirm that there are statistically significant differences between the final exam scores from both groups, being that the b-learning group achieved higher scores.

\section{Discussion and conclusion}

In this paper, we discussed the comparison between two groups of students under the same therapeutics curriculum, with the same teachers, same length and topics covered. One group was taught face-to-face and another, in blended learning. As stated above, the group and individual assessments were made in both cases, but there were significant differences regarding the strategies uses in face-to-face and in blended learning. The only assessment strategies that remained the same, was the written test that provided an objective value for comparison.

The existing literature on blended learning for the teaching of pharmacy students is not extensive, but can already lead to a comparative analysis with the study developed here. A similar experiment was presented by Crouch [47] on the learning process of cardiovascular pharmacotherapy in a blended learning approach. As in our case, training was established over several weeks, and the evaluation process carried out with online quizzes (8) and a written evaluation. Forty five sessions were scheduled. Students had to collaborate in the online sessions and to make specific presentations in the face-to-face sessions. Analysing the marks obtained by students in APPE examinations (Advance Pharmacy Practice Experience), it appears that students who chose the blended learning methodology reached higher values. Still regarding health professional's education, but in Respiratory Care, Strickland [48] proposed to analyse the performance of students through their final grade in classroom training and b-learning. Although the performance of students in b-learning was higher, it was not statistically significant. It should be mentioned that this study referred only to a group of 14 students, which is probably one of its biggest limitations. Still with students of pharmacy and using a case based learning approach, Lapidus et al. [49] sought to test the effectiveness of blended learning approach (compared to face-to-face) in student performance in terms of capacity for drug literature evaluation. With an $N$ of 909 , students were divided into three different groups, and no significant differences were found in the final grade of the course. However, we should safeguard that in this case there was no final examination, assessment consisted of a set of papers/presentations, and there were several teachers involved with the different groups of students, which in itself can cause variability in the results. In a similar context, Suda et al. [50] aimed to evaluate student pharmacist experience and academic performance in the first offering of a drug information and literature evaluation course utilising a blended learning approach. Their strategy allowed for an increase in active learning sessions, higher course grades, and improvement in components of the course evaluations. Regarding the effectiveness of the use of blearning, for the learning process of topics related to Pharmacy [51-56] or other health sciences [57-59], the conclusions are consistent. In the cited cases, the evidence suggests that the blended learning scheme is effective in teaching future health professionals.

Besides the use of test scores, all cited literatures explore the use of other assessment methods. In our case, the forum was the 
one that provided less information. Although it was explored in two separate sessions, the forum had a relatively low participation. Comparing the access statistics, with effectively placed contributions, it was confirmed that the majority of students visited the forum and the topics, but did not actively participated in the discussion. Cunha [60] elaborates on this type of behaviour, stating that often students feel inhibited, whereas the text 'posted' will be accessible to teachers and colleagues. In addition, it should be considered that for many of these students this was their first experience in distance education, where students are not yet familiar with their relevant role in the learning process [61], nor often use some of the necessary Web tools necessary for online education [62].

Munoz Organero and Kloos [42] also debate this issue and present other valid points regarding low participation in the forums. According to the authors 'sharing knowledge can be seen as a waste of competitive advantage, especially if students consider e-learning courses as a competition to try to be the best of the class. The lack of time is another negative contributor for the students' participation in forums. This is even more relevant for students that have better intellectual skills, since they receive little from their participation in forums as compared to other ways of learning.'

This, points out to a very important fact in the use of forums: students must be motivated for using them. Strategies like peer review, commend relevant contributions and guarantee an active presence of the teacher can be used. The use of a provocative argument to start the discussion or even launch challenges are other strategies that have been previously described [63].

Despite the compelling data obtained from the literature, the main objective of this paper was not to prove the superiority of blended learning in the teaching of therapeutics. Much more important it is to demonstrate that these initiatives can be achieved effectively, following pre-established teaching methods and above all and as demonstrated, do not negatively affect student performance. Moreover, we should not focus only on results and tests scores, but also provide new learning environments and strategies, and promote the development of new skills to learn and collaborate online, which may be relevant in a networked knowledge society and in a context of lifelong learning. These aspects are important for their formative nature, and, in our understanding, already justify this study.

\section{References}

[1] Jesus, Â., Gomes, M.J., Cruz, A.: 'A case based learning model in therapeutics', Inov. Pharm., 2012, 3, (4), pp. 1-12, Article 91

[2] Jesus, Â., Cruz, A., Gomes, M.J.: 'Case based, learner centered approach to pharmacotherapy', Proceedings of EDULEARN11 Conference. Barcelona, Spain, 2011, 3, (4), pp. 6074-6080

[3] Dewey, J.: 'Democracy and education' (Free Press, New York, 1997)

[4] Neufeld, V.R., Barrows, H.S.: 'The 'McMaster philosophy': an approach to medical education', J. Med. Educ., 1974, 49, (11), pp. 1040-1050

[5] Cisneros, R.M., Salisbury-Glennon, J.D., Anderson-Harper, H.M.: 'Status of problem-based learning research in pharmacy education: a call for future research', Am. J. Pharm. Educ., 2002, 66, (1), pp. 19-26

[6] Jesus, Â., Gomes, M.J.: 'Case-studies, problem based learning and simulations in biomedical teaching - a literature review', EduSer, 2013, 5, (1), pp. $28-50$

[7] Williams, B.: 'Case based learning — a review of the literature: is there scope for this educational paradigm in prehospital education?', Emerg. Med. J., 2005, 22, (8), pp. 577-581

[8] Schmidt, H.G.: 'Assumptions underlying self-directed learning may be false', Med. Educ., 2000, 34, (4), pp. 243-245

[9] Jesus, Â., Gomes, M.J., Cruz, A.: 'A B-learning strategy for therapeutics at the bachelor level', 2012

[10] Barrows, H.S.: 'A taxonomy of problem-based learning methods', Med. Educ., 1986, 20, (6), pp. 481-486

[11] Garvey, M.T., O'Sullivan, M., Blake, M.: 'Multidisciplinary case-based learning for undergraduate students', Eur. J. Dent. Educ. Off. J. Assoc. Dent. Educ. Eur., 2000, 4, (4), pp. 165-168

[12] Gambrill, E.: 'Wiley: critical thinking in clinical practice: improving the quality of judgments and decisions' (John Wiley \& Sons, 2012, 3rd edn.)

[13] Carreira, R.P., Dominguez, C., Monteiro, M.J., et al.: 'Application of the ADAPTED FRISCO framework in case-based learning activities', Rev. Lusófona Educ., 2016, 32, (32), pp. 175-191

[14] Pastirik, P.J.: 'Using problem-based learning in a large classroom', Nurse Educ. Pract., 2006, 6, (5), pp. 261-267

[15] Wassermann, S.: 'Introduction to case method teaching: a guide to the galaxy' (Teachers College Press, 1994)

[16] Dick, W., Carey, L., Carey, J.O.: 'The systematic design of instruction' (Allyn \& Bacon, 2004, 6th edn.)
[17] Gomes, M.J.: 'Contextos e Práticas de Avaliação em Educação Online', Miranda, G.L. (Ed.): (Relógio D'água, 2009), pp. 125-153

[18] Jesus, Â., Gomes, M.J., Cruz, A.: 'Case based learning digital: estratégias de avaliação e colaboração online', Indagatio Didact., 2013, 5, (3), pp. 126-141

[19] Dikli, S.: 'Assessment at a distance: traditional vs. alternative assessments', Turkish Online J. Educ. Technol., 2003, 2, (3), pp. 13-19

[20] MacDonald, J.: 'Blended learning and online tutoring planning learner support and activity design' (Gower, Aldershot, Burlington, VT, 2008)

[21] Thorne, K.: 'Blended learning how to integrate online \& traditional learning' (Kogan Page, London, Sterling, VA, 2003)

[22] Bersin, J.: 'The blended learning book: best practices, proven methodologies, and lessons learned' (Pfeiffer, San Francisco, CA, 2004)

[23] Whitelock, D., Jelfs, A.: 'Editorial. Special issue on blended learning journal of educational media', J. Educ. Media, 2003, 28, (2), pp. 99-100

[24] Driscoll, M.: 'Blended learning: let's get beyond the hype', 2002

[25] Lencastre, J.A.: 'Blended learning: a Evolução de um Conceito', in 'Blended learning em Contexto Educativo' (DE FACTO Editores, Santo Tirso, 2012), pp. $151-172$

[26] Reay, J.: 'Blended learning - a fusion for the future', Knowl. Manag. Rev., 2001, 4, (3)

[27] Sands, P.: 'Inside outside, upside downside: strategies for connecting online and face-to-face instruction in hybrid courses', Teach. Technol. Today, 2002, $8,(6)$

[28] Tu, C.-H., McIsaac, M.: 'The relationship of social presence and interaction in online classes', Am. J. Distance Educ., 2002, 16, (3), pp. 131-150

[29] Young, J.R.: "Hybrid' teaching seeks to end the divide between traditional and online instruction', Chron. High. Educ., 2002, 48, (28)

[30] Garrison, D.R., Kanuka, H.: 'Blended learning: uncovering its transformative potential in higher education', Internet High. Educ., 2004, 7, (2), pp. 95-105

[31] Bonk, C.J., Graham, C.R.: 'The handbook of blended learning: global perspectives, local designs' (Wiley, 2006)

[32] Krause, K.-L.: 'Beyond classroom walls: Students' out-of-class activities and implications for teaching and learning', Nagoya J. High. Educ., 2007, 7, pp. 301-318

[33] Jesus, Â., Gomes, M.J., Cruz, A.: 'Case based learning digital - Proposta para Estruturação da Formação’, 2013, pp. 6433-6441

[34] Brindley, J., Blaschke, L.M., Walti, C.: 'Creating effective collaborative learning groups in an online environment', Int. Rev. Res. Open Distance Learn., 2009, 10, (3), pp. 1-18

[35] Conole, G.: 'Facilitating new forms of discourse for learning and teaching: harnessing the power of Web 2.0 practices', Open Learn. J. Open Distance Learn., 2010, 25, (2), pp. 141-151

[36] Vázquez, E., Fombona, J., Fernández, A.: 'Virtual attendance: analysis of an audiovisual over IP system for distance learning in the Spanish Open University (UNED)', Int. Rev. Res. Open Distance Learn., 2013, 14, (3), pp. 402-426

[37] Peres, P., Pimenta, P.: 'MIPO model: a framework to help the integration of web technologies at the higher education', in Kidd, T.T., Keengwe, J. (Eds.) 'Adult learning in the digital age' (IGI Global, 2009)

[38] Raman-Wilms, L.: 'Applying therapeutic knowledge and skills in a large group problem-based class', Am. J. Pharm. Educ., 2005, 69, (5)

[39] Mason, R.: 'Models and methodologies in distance education', 2003

[40] McNaught, C., Lam, P., Ong, D., et al.: 'Challenges in assessments in a casebased science course', Frankland, S. (Ed.): (Springer, Dordrecht, 2007), pp. 256-264

[41] Mardanian, H., Mozelius, P.: 'A reliable, efficient, affordable and userfriendly approach for online assessment in distance education' EDEN Open Classroom Conference, Greece, 2011

[42] Munoz Organero, M., Kloos, C.D. 'Using forums and assessments as motivational tools in E-learning courses: a case study', 2007, pp. T2D-1T2D-6

[43] Yang, Y.-T.C., Newby, T.J., Bill, R.L.: 'Using Socratic questioning to promote critical thinking skills through asynchronous discussion forums in distance learning environments', Am. J. Distance Educ., 2005, 19, (3), pp. 163-181

[44] Campbell, D.T., Stanley, J.: 'Experimental and quasi-experimental designs for research' (Cengage Learning, 1963, 1st edn.)

[45] Eccles, M., Grimshaw, J., Campbell, M., et al.: 'Research designs for studies evaluating the effectiveness of change and improvement strategies', Qual. Saf. Health Care, 2003, 12, (1), pp. 47-52

[46] Steiner, P.M., Wroblewski, A., Cook, T.: 'Randomized experiments and quasiexperimental designs in educational research', 'The SAGE international handbook of educational evaluation' (SAGE Publications, Inc, 2009)

[47] Crouch, M.A.: 'An advanced cardiovascular pharmacotherapy course blending online and face-to-face instruction', Am. J. Pharm. Educ., 2009, 73 (3), p. 51

[48] Strickland, S.: 'Achieving course goals in an undergraduate healthcare ethics course: a comparison of three course delivery methods'. Global Learn 2011, 2011, no. 1, pp. 2268-2272

[49] Lapidus, M., McCord, S.K., McCloskey, W.W., et al.: 'Combined use of online tutorials and hands-on group exercises in bibliographic instruction for pharmacy students', Med. Ref. Serv. Q, 2012, 31, (4), pp. 383-399

[50] Suda, K.J., Sterling, J.M., Guirguis, A.B., et al.: 'Student perception and academic performance after implementation of a blended learning approach to a drug information and literature evaluation course', Curr. Pharm. Teach. Learn., 2014, 6, (3), pp. 367-372

[51] Zapantis, A., Machado, C., Nemire, R., et al.: 'An elective course in adult acute care medicine using a hybrid delivery system', Am. J. Pharm. Educ., 2008, 72, (5)

[52] Munson, C.E.: 'Assessment of the efficacy of blended learning in an introductory pharmacy class' (ProQuest LLC, 2010)

[53] Hope, D., Hattingh, L., Haywood, A.: 'Safe dispensing practice: development and evaluation of a blended learning tool to enhance dispensing in pharmacy 
practice education' (Iated-Int Assoc Technology Education and Development, Valenica, 2011)

[54] Karamizadeh, Z., Zarifsanayei, N., Faghihi, A.A., et al.: 'The study of effectiveness of blended learning approach for medical training courses', Iran. Red Crescent Med. J., 2012, 14, (1), pp. 41-44

[55] Spedding, R., Jenner, R., Potier, K., et al.: 'Blended learning in paediatric emergency medicine: preliminary analysis of a virtual learning environment', Eur. J. Emerg. Med., 2013, 20, (2), pp. 98-102

[56] Hughes, P.J., Waldrop, B., Chang, J.: 'Student perceptions of and performance in a blended foundational drug information course', Curr. Pharm. Teach. Learn., 2016, 8, (3), pp. 359-363

[57] Dantas, A.M., Kemm, R.E.: 'A blended approach to active learning in a physiology laboratory-based subject facilitated by an e-learning component', Adv. Physiol. Educ., 2008, 32, (1), pp. 65-75

[58] Arroyo-Morales, M., Cantarero-Villanueva, I., Fernandez-Lao, C., et al.: 'A blended learning approach to palpation and ultrasound imaging skills through supplementation of traditional classroom teaching with an e-learning package', Man. Ther, 2012, 17, (5), pp. 474-478

[59] Grasl, M.C., Pokieser, P., Gleiss, A., et al: 'A new blended learning concept for medical students in otolaryngology', Arch. Otolaryngol. Neck Surg., 2012, 138, (4), pp. 358-366

[60] Cunha, A.: 'Interação verbal em fóruns de discussão: a língua escrita em atividades colaborativas', 2007

[61] Lencastre, J.A., Monteiro, A., Moreira, J.A., et al.: 'Blended learning: a Evolução de um Conceito' (DE FACTO Editores, Santo Tirso, 2012), pp. $151-172$

[62] Galusha, J.M.: 'Barriers to learning in distance education', 1998

[63] Oliveira, L., Jesus, Â., Silva, A., et al.: 'Conceção De Cursos Em Regime e/bLearning: Uma Experiência De Formação E Tutoria Online Numa Turma De Grande Dimensão'. Proc. of the IX Int. Conf. on ICT in Education, 2015 